\title{
Peer review and the US Immigration process
}

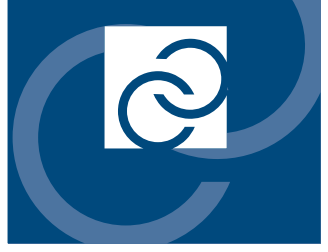

By Marco Pignone

$\mathrm{I}_{\mathrm{i}}^{\mathrm{i}}$ you have read my prior articles, or have some familiarity with the US Immigration process, then you know that to win a green card through an EB-1A or EB-1B petition, you have to "win" or meet three out of 10 major evidence categories. These categories also apply to EB-2/National Interest Waiver (NIW) petitions. I will not review the entire list in this article, but instead will focus on one specific category: peer review.

For anyone applying for a green card through an EB-1 or EB-2/NIW petition, peer review is the key to winning one of the major evidence categories called "Judging the Work of Others." While it is more significant in the EB-1A and EB-1B categories, it is still important for an EB-2/NIW case.

If you are from China or India, you are probably aware of the extremely long wait times in the EB-2/NIW category. Nearly every one of our clients with an approved EB-1 case used "Judging the Work of Others" as one of their required three categories. On occasion, someone may have a good argument for a fourth or fifth category (media being the most common fourth category), but in general, you must prove that you have "served as a judge of the work of others," most commonly through peer review, and if you cannot win that category, your odds are very low.

As an example, a potential client sent us a Notice of Intent to Deny his EB-1B petition. EB-1B petitions are usually for scientists working in academia. Generally, they are slightly easier to win than EB-1A petitions, but the Immigration Service applies a much higher standard to EB-1B petitions than EB-2/NIW petitions. Some people think the EB-1B category is "easy to win" because a university files the petition, but one should not underestimate the qualifications required to convince the Immigration Service to approve an EB-1B petition.

This potential client's "Notice of Intent to Deny" noted that he had reviewed only eight papers for one specific journal. While this may be sufficient in a NIW case, it certainly is not in either the EB-1A or EB-1B categories.

The first thing you should know is that you must complete peer review in your own name, not merely assisting your supervisor in doing peer review. Further, the impact factor of the journal is irrelevant. The Immigration Service considers quantity to be much more important than quality.

While the total number of times you have completed peer review is the most important factor, you should not review for only one journal. Contact as many journals as possible and offer to complete peer reviews to maximize your chances of being accepted to a broader range of journals. Then focus on increasing the quantity of peer reviews.

It is difficult, and we do not see this often, but being on the editorial board of a journal is given much greater weight than merely completing peer review. This can be very helpful in EB-1A cases, and if you are given the opportunity to serve as an editor, you should certainly accept that offer. If this requires a lot of your time, you should know that it might not make much of a difference in an EB-2/NIW petition.

Aside from doing peer review, the next most common way of winning the category is by judging conference submissions, but this is relatively unusual in our experience. Further, on rare occasions, we have seen clients who judged applications for grants or research funding. This situation arises when, for example, a government organization, such as the National Institutes of Health, or private philanthropic organizations, such as the Gates Foundation, employs researchers to evaluate grant submissions. Again, this is rare, and you should not think that this is necessary to win the category. The vast majority of even the most qualified EB-1A petitioners tend to use only peer review. How do you prove that you did peer review? Our law firm always submits:

1. Emails from the journals inviting you to perform a peer review.

2. The email that you sent to the journal with your work product.

3. The email from the journal thanking you for doing the peer review.

4. A letter from the journal on letterhead discussing their criteria for selecting peer reviewers, and why they specifically selected you for that position. Again, we submit all four of the above in each case.

Many people fail to include the letter from the journal, but I believe this to be a significant piece of evidence, as it gives you an opportunity to include the criteria setting you apart from others who were not selected. You may contact me using the information at the end of this article for examples of the email evidence discussed.

Marco Pignone, immigration lawyer at the Philadelphia law firm Getson \& Schatz, P.C. (https://researcher greencard.com/), currently focuses on EB-1A and NIW petitions for immigrant researchers. Since 2001, he has represented immigrants in a wide range of immigration matters. 